\title{
Mini review on organic cotton
}

\begin{abstract}
Cotton fiber is one historic, traditional, familiar, and well known natural fiber which is one of the highly consumable fiber types. Conventional cotton growing requires high amount of chemical fertilizers and pesticides. In a rough estimation approach, the amount of total fertilizer consumption in weight is reported as $33 \%$ of the annual raw cotton output. The awareness and responsible behaviors are started to be an important concern among the consumers and governments in the 80 's all over the world in all sectors, together with fiber and textile sectors. Some precautions are taken into consideration in manufacturing, processing, consumption, and waste processing stages in textile and clothing sectors, that organic cotton growing was one worldwide applied action. Organic cotton is grown using well defined methods and controlled auxiliaries that have low impact on the environment. The goal of organic fiber growing is to protect the natural sources and human health, besides all animals, plantation, and sustainable life conditions. Organic growing systems replenish and maintain soil fertility, reduce the use of toxic and persistent pesticides and fertilizers, and build biologically diverse agriculture. Certification of organic fibers needs some hard procedure such as ceasing the use of pesticides, chemical fertilizers before three years subsequent organic cultivation; using only permissible substances; covering physically the borders of cultivation fields; cultivating some trap plants if necessary; using organic manure, and organic soil enrichment. The organic cotton becomes a new business prospect that more than 30 textile brands have already introduced their organic cotton textile and clothing collections. The organic cotton business is predicted to become a constantly widening issue in the future.
\end{abstract}

Keywords: cotton fiber, organic cotton, world textile sector, environment
Volume 3 Issue 2 - 2017

\section{Nalan Devrent, Sema Palamutcu}

Department of Textile Engineering, Pamukkale University

Engineering Faculty, Turkey

Correspondence: Sema Palamutcu, Department of Textile Engineering, Pamukkale University Engineering Faculty, Denizli, Turkey, Tel 25829631 I0, 25829632 62,

Email spalamut@pau.edu.tr

Received: July 26, 2017 | Published: October 27, 2017

\section{Introduction}

Organic cotton is a member of textile fiber product tree, where natural and manmade fiber groups are two main branches. Natural and man-made textile fiber consumption in the world is over 85 million tons annually. Amount of manmade fiber consumption, including polyester, is increasing constantly while share of cotton fiber fluctuates in a narrow band (Figure 1). Feature fiber consumption estimations have also exhibited that amount of man-made fiber consumption is going to increase until 2020 and probably will continue to increase. Organic cotton consumption ratio in the total conventional cotton consumption has only about the level of $0.4 \%$ in the annual conventional cotton yield of 26,28million tons in 2014 (Table 1). Table I World cotton supply, (000 kg) ${ }^{2}$

\begin{tabular}{|c|c|c|c|c|c|c|}
\hline S. no & Country & $2011 / 12$ & $2012 / 13$ & $2013 / 14$ & $2014 / 15$ & $2015 / 16 *$ \\
\hline 1 & India & 6001 & 6095 & 6770 & 6510 & 6240 \\
\hline 2 & China & 7400 & 7300 & 6929 & 6480 & 5260 \\
\hline 3 & USA & 3391 & 3770 & 2811 & 3550 & 2820 \\
\hline 4 & Pakistan & 2294 & 2204 & 2076 & 2310 & 1610 \\
\hline 5 & Brazil & I 884 & $|26|$ & 1705 & 1550 & 1550 \\
\hline 6 & Uzbekistan & 880 & 1000 & 940 & 890 & 860 \\
\hline 7 & Turkey & 750 & 858 & 760 & 847 & $* 779$ \\
\hline 8 & Australia & I 225 & 1018 & 890 & 450 & 470 \\
\hline & other & 3459 & 3332 & 3402 & 3543 & 3051 \\
\hline & Total & 27284 & 26838 & 26283 & 26130 & 22640 \\
\hline
\end{tabular}




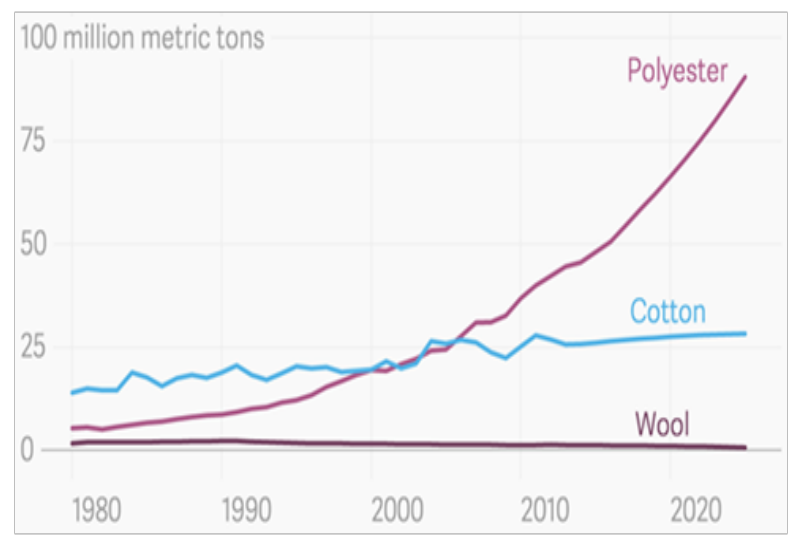

Figure I World Fiber production.'

Cotton as the main consumable natural fiber type has been grown in different regions of the world. Main cotton fiber growing countries in the World are listed in Table 1 where Turkey has the 7 th place after India, China, USA, Pakistan, Brazil, and Uzbekistan.

Annual cotton fiber production is not constant, as it is shown in the Figure 2, total cotton farming area and also average cotton yield in $\mathrm{kg} / \mathrm{Ha}$ are fluctuate depending on the local and international market conditions. As it is given in the table, annual cotton fiber production has decreased in 2015/2016 season at about 13\% comparing to the previous season and realized as 22,64 million tones. Reason of the decrease can be explained via several different factors, where the most influential ones are decrease of total farming are in the world; decrease of average yield (Figure 2), and total decrease in China, USA and Pakistan.

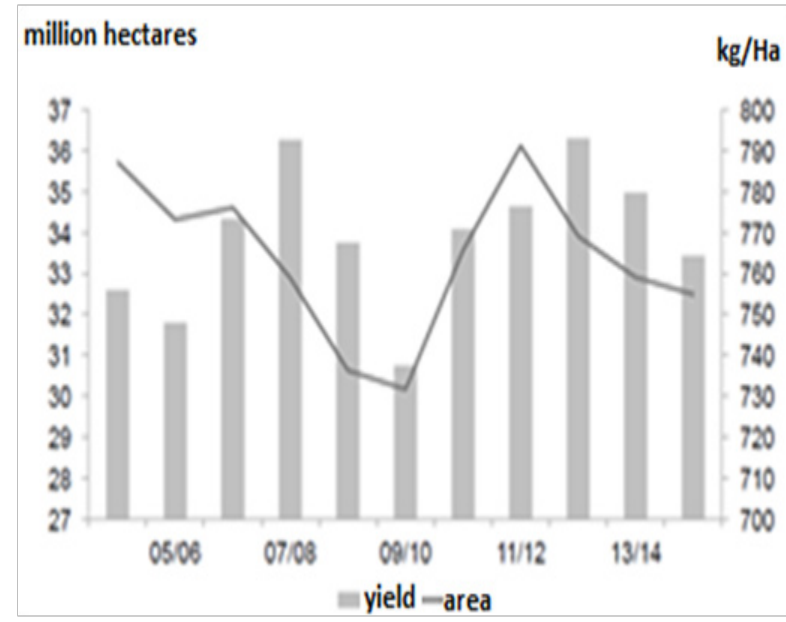

Figure 2 World cotton area and yield. ${ }^{3}$

Cotton cultivation is reported as one of the main pesticide and herbicide consuming cultivation, resulting some dramatic environmental influences. Cotton is cultivated in many developing countries, occupying less than $3 \%$ of world's agricultural land in total. It is an intensive process that always requires huge applications of agrochemicals which account for about $20 \%$ of all agricultural chemicals used in the world. In case of Turkey, it has been reported that annual pesticide consumption in all agricultural activities is about 30,000 metric tons ${ }^{4}$ where average consumption is $0.5 \mathrm{~kg}$ per hectare, which is lower than the average consumption of developed countries. However, consumption of pesticide is not homogenously dissipated in Turkey. $40 \%$ of pesticides are used in the cotton farming areas of Adana, Mersin and Antalya regions. Adding Izmir and its peripheral regions to the consumption, the total share reaches up to the $65 \%$. About $29 \%$ of all pesticides used in Turkey are used on cotton agriculture. These regions account for about $40 \%$ of total cotton area in Turkey. Therefore, about $40 \%$ of Turkish cotton is subject to relatively heavy pesticide applications. On the other hand, southeast Turkey, which accounts for $60 \%$ of cotton production in Turkey, accounts for just $7 \%$ of pesticide use on cotton.

High amount of chemical use in the cotton cultivation in the world has driven the consumer to look for some other alternative textile fibers. Organic farming and organic cotton growing are accepted as one alternative environmental friendly fiber. Increasing awareness for social and environmental issues among consumers and companies has led to strong growth of the organic cotton market over the past decade.

\section{Organic cotton cultivation}

Organic cotton cultivation is a well-known old cultivation where only natural fertilizers or registered/controlled list of chemical fertilizers are allowed to be used on the land and its neighboring area. Practically organic cotton growing countries in the world are listed Table 2 and shown in the world map, Figure 3.

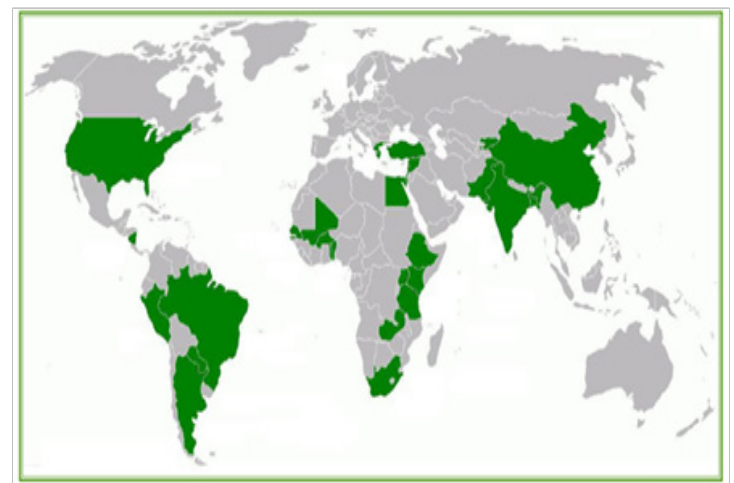

Figure 3 Countries growing organic cotton. ${ }^{7}$

According to Textile Exchange Group, approximately 637,563 bales of organic cotton were produced on 783,094acres around the globe in 2011-2012. The group reported a decrease in organic cotton production of $21 \%$ in 2013 , where India was the largest producer, followed by (in order of rank) China, Turkey, Tanzania, the United States, Burkina Faso, Egypt, Mali, Uganda and Peru. However, the organization notes that due to the conflict in Syria (which typically ranks second or third in world organic cotton production), no figures were available for Syria. ${ }^{6}$

Organic cotton fiber has become one consumable fiber group since last 25years in order to maintain protection on ecosystems and sustainable environment; healthier farmers and consumers, cheaper agricultural inputs, more variety and added value textile items; better quality; and better feeling of better treatment to environment.

First attempt to grow organic cotton in the world have started in early 1980's with the first certification programs in the European Countries. First organic agricultural practices were employed in Turkey during middle of 1980's on growing organic dried fruits for which Turkey is famous with its ecological variety in these products and this was driven by demand from European importers and retailers. Pioneering products were dried fruits and nuts and cotton has joined 
them literally later on. The first serious attempt for organic cotton production has started in Turkey to include cotton as a rotation crop and also to prove that organic farming should not be limited to only food production. ${ }^{7}$

Cotton cultivation is monoculture cultivation, but in organic cotton cultivation, rotation with other crops of cereals and legumes can be cultivated. Mainly there are not dramatic differences between conventional and organic cotton cultivation in the schedule. In the organic cotton growing, farmers need to be educated about the organic cultivation concepts, standards, rules, practices and implementations. Organic production standards vary depending on the cotton harvesting governments and regions. The most commonly adopted standards are the European Union's EU 2092/91 standard, the United States Department of Agriculture's National Organic Program Standard and the Japanese Agricultural Services' JAS standard. Certification process Table 2 Organic cotton growing country rank in the World yield ${ }^{5}$ is compiled via independent agencies to ensure that cultivation works has meet the requirements.

Turkey is a pioneer in producing organic cotton. ${ }^{9}$ Organic cotton production started in Turkey in Kahramanmaras in the Eastern Mediterranean region in 1989/90, where statistical data has only started to be recorded in 2002 (Table 3). The project was called Good Food Foundation and was followed by a second multinational project initiated in Salihli (Manisa) in the Aegean region by Rapunzel, a German company. Turkey significantly increased its organic cotton production during $1999 / 00$ and 2000/01seasons. Turkey alone produced about 10,000tons of organic cotton in 1999/00 and 2000/01seasons. In Turkey, there are small growers owning 15-20 hectares who produce organic cotton, and on average organic cotton growers suffered a 5,4 -7,4\% reduction in yield.

\begin{tabular}{llllll}
\hline S. no & $\mathbf{2 0 0 7 / 0 8}$ & $\mathbf{2 0 0 8 / 0 9}$ & $\mathbf{2 0 0 9 / 1 0}$ & 20I0/II & 20I I/I 2 \\
\hline $\mathbf{I}$ & India & India & India & India & India \\
2 & Syria & Turkey & Syria & Syria & Turkey \\
3 & Turkey & Syria & Turkey & China & China \\
4 & China & Tanzania & China & Turkey & Tanzania \\
5 & Tanzania & China & USA & USA & USA \\
6 & USA & USA & Tanzania & Tanzania & Mali \\
7 & Uganda & Uganda & Uganda & Egypt & Peru \\
8 & Peru & Peru & Peru & Mali & Uganda \\
9 & Egypt & Egypt & Egypt & Kyrgyzstan & Egypt \\
10 & Burkina Faso & Burkina Faso & Mali & Peru & Burkina Faso \\
\hline
\end{tabular}

Table 3 Organic cotton production in Turkey between 2002-20078

\begin{tabular}{lllllll}
\hline & 2002 & 2003 & 2004 & 2005 & 2006 & 2007 \\
\hline Number of registered organic growers & 12428 & 13044 & 9314 & 9427 & 9314 & 10553 \\
Total organic farming land, (hectares) & 89826 & 103190 & 162192 & 175073 & 162131 & 135359 \\
Total quantity of organic products, (tons) & 310121 & 291875 & 279663 & 289082 & 309521 & 431202 \\
\hline
\end{tabular}

Turkey has a full chain of organic cotton products and most organic cotton is grown and processed to produce summer clothing, T-shirts, baby wear, towels and home textiles. Interest on the organic cotton consumption has raised in developed countries of the World during the last 20years with the help of worldwide known textile and clothing brands. The bulk of the organic cotton fiber production is consumed by companies with large organic textile programs such as C\&A, Nike, Walmart/Sam's Club, Williams-Sonoma, Inc., H\&M, Anvil Knitwear, Coop Switzerland, Green source, Levi Strauss \& Co., Target, Adidas, Nordstrom (2009, in descending order). In addition, more than thousand smaller companies, as well as companies with smaller organic textile programs, consume and sell organic cotton products..$^{10}$ Top 10 users of organic cotton by volume include H\&M, C\&A, Puma, Nike, Decathlon, Tchibo, Coop Swiss, Target, WilliamsSonoma and Inditex (Zara). ${ }^{11}$ According to the organic cotton market report (OCMR) of textile exchange, ${ }^{12}$ organic cotton market value has reached up to 15,7 billion USD, with $22 \%$ increase in GOTS certified facilities and $10 \%$ of increase in organic cotton production.

\section{Transformation of the organic cotton to the organic textile}

Organic cotton has processed as it is in conventional cotton processing in ginning, pressing and baling processes. Packing material that is used to cover the organic cotton should be chosen among organic cotton based textile fabrics. During the spinning process, the only point that is needed to be considered is elimination of any previous fiber contamination risk to the organic cotton fiber blend. Weaving preparation phase requires special care in the sizing process where only appropriate sizing agents are required. Weaving and knitting phases are regular as it is in conventional cotton processes. When it comes to wet processing of the dyeing and finishing processes, only allowed chemicals should be used to accomplish finishing processes on organic cotton fabric.

Organic textile production stages are also strictly controlled and certified from the raw cotton stage all the way through the conventional spinning, knitting/weaving, wet processing, and cut/ 
sew stages as it is in organic cotton cultivation. The most commonly applied certification program in organic textiles are GOTS (Global Organic Textile Standards), OEKOTEX 100, ${ }^{13}$ and the Nordic Swan Ecolabel. ${ }^{14}$

\section{Limitations and opportunities in the organic cotton markets}

Cotton growing in organic method has some limitations which are fertilizer use; pest control; production control; lack of information on cost of production; price premium; tied crop rotation; marketing; and certification. ${ }^{15}$

Normally used fertilizers are synthetic fertilizers containing different variety of nutrients based on N, P, and K. Green manuring and organic fertilization can be employed to maintain the required nutrient supply, instead of synthetic fertilizers however it should be controlled that the availability of nitrogen to the level of inorganic fertilization. $\mathrm{P}$ and $\mathrm{K}$ can be sufficiently achievable in green manuring.

Insect and pest control requirements are high because of the variety of bugs which are going to attack under organic growing conditions. Biological controls can be utilized to compensate for the lack of insecticide use. The cotton plant has one of the best built-in compensation systems of many field crops. It can make up for early losses, but it cannot make up for a loss suffered after a certain time because cotton growing conditions have a certain cut-out period when the plant ceases to bear more flowers and bolls. Hence, it is necessary to find alternate means of insect control.

Production control is an asset in most of the cotton growing to maintain crop control. Technology package that includes the best use of inputs and production practices are free and delivered directly by the extension service to farmers' doorsteps. The advice, or technology package, on how a producer can achieve maximum yield includes guidance, from variety selection, planting time, soil preparation, elimination of weeds, irrigation, insect control, all the way to picking and storage of seed cotton until it is sold. In case of organic cotton growing farmers need advice, without which they can be risking their investment. Unfortunately, whatever little advice on organic cotton is available is not authenticated or equivalent to conventional production technology packages. It is wrong to assume that the elimination of fertilizers, pesticides and other agrochemicals would simplify cotton production practices.

Lack of Information on Cost of Production of organic cotton is one main hesitating point from the view of farmers and governments. When fertilizers and insecticide were first adopted in most countries, cotton yields started to increase. Cost of synthetic additives results increase on unit cotton production cost while sale price of the cotton is not changing. Such case enforces conventional cotton farmers to ignore synthetic additives, which cause additional cost, and move to the organic cotton growing. Organic production practices generally lower costs of production per unit area. But the economics of reducing expenditures incurred in growing a unit area are determined by the effect on yield. Lower total costs per hectare do not mean lower costs per $\mathrm{kg}$ of lint, if the elimination of prohibited agrochemicals significantly reduces yield/hectare. It is generally accepted that the elimination of synthetic agrochemicals will affect yields, but the impact on yields and the cost of production have not been established. Potential organic cotton growers will definitely consider the economics of growing organic cotton versus conventional production before making a decision. Unfortunately, information on cost of production of organic cotton versus conventional production under various sets of production conditions is not available. In the absence of such information, farmers are reluctant to adopt organic production.

Price Premium is an optimistic expectation for the organic cotton farmers. However, it has been seen that organic producers have not received premiums, and sometimes they have been penalized for growing lower grade cotton because of boll-worm damage. Data have been collected for over ten years in many countries, but there is no conclusion regarding the average premium or discount on organic cotton versus conventional cotton. Without a price premium, organic cotton will not be profitable because of reductions in yield. Solid indications that price premiums can be expected would encourage organic production.

Tied Crop Rotation plans are one inevitable option in organic cotton growing. General principle of rotation in planting says that deep-rooted crops should be followed by shallow-rooted crops. But once a cotton field becomes eligible for full certification, usually after a transitional period of three years, it must be planted only with organic crops when cotton is not in the field. Thus, cotton must rotate with another organic crop, or the field should be left follow for recuperation of soil fertility, which may not be acceptable under the current pressure for high cropping intensity. If an organic cotton producer is willing to plant a rotation crop, he has to learn how to produce the second crop under organic conditions also.

Certification and labeling are areas that need attention. Certification is an additional cost and in some cases organic producers have complained about it.

Marketing is the most sensitive aspect of organic cotton production and expansion lies in marketing, and market linkages between cotton producers and international buyers, ranging from access to market information and distribution channels.

Organic cotton growing business brings its opportunities with its number of limitations. According to the U.S. organic cotton growers, there are opportunities to benefit from the development of the subjects given in the Table 4.

Table 4 Opportunities in organic cotton growing business

I Organic weed controls

2 Cotton seed varieties better suited to growing conditions

3 Marketing efforts to increase consumer demand for U.S.-grown organic cotton

4 Market development to encourage better gate pricing

5 Improved awareness of the GOTS label within the U.S. market

6 Continued improvements to crop insurance

7 Streamlined administrative process for the organic grower

8 Tax credits, certification cost share and other financial incentives to encourage organic production 


\section{Conclusion}

Organic cotton still only occupies a tiny niche of less than $0,5 \%$ of global cotton production. However, the number of farms converting to organic cotton and the number of projects is constantly increasing. At present, organic cotton cultivation is reported in the following countries listed in Table 5. ${ }^{16}$

There are a number of reasons to grow cotton organically. The negative impacts of conventional cotton farming on the environment and health are obvious and well known. Cotton as a fiber is used in textile production which is not used as food, while the seed of the cotton plant is consumed to be processed to edible oil and cattle feed. At the fact that around $60 \%$ of the cotton weight harvest is cotton seed, which encounters about 15 million tons, is processed and it enters the human food chain. We also know that the pesticides sprayed on cotton do not only affect the target pest. Beneficial insects and other animals are killed, too, so that pests that formerly were of minor importance now have become a major problem (for ex-ample, whitefly and aphids). In addition, many of the farmers and labors face health problems that cause them to miss a lot of work and have additional costs for medical treatment.

Increasing demands on world fiber consumption enforces manufacturers to produce more synthetic fibers which is mainly polyester. Share of natural fiber types, where cotton has about $97 \%$ of it, in the total world fiber consumption is decreasing. Organic cotton fiber market is having more attention on the markets of developed countries where consumer purchasing power is high. However increasing market share of the organic cotton products is not relevant to the volume organic cotton growers and organic textile and clothing manufacturers and designers yet.

Table 5 Organic cotton cultivating countries

\begin{tabular}{ll}
\hline Africa: & $\begin{array}{l}\text { Benin, Burkina Faso, Egypt, Mali, } \\
\text { Mozambique, Senegal, Tanzania, Togo, } \\
\text { Uganda, Zambia, Zimbabwe }\end{array}$ \\
Asia: & China, India, Kyrgyzstan, Pakistan \\
South America: & $\begin{array}{l}\text { Argentina, Brazil, Nicaragua, Paraguay, } \\
\text { Peru }\end{array}$ \\
Middle East: & Turkey, Israel \\
Europe: & \\
North America & Greece \\
Australia & \\
\end{tabular}

\section{Acknowledgements}

Authors extend their sincere appreciation to the anonymous referees for their useful suggestions. Authors also want to mention that the names of companies or commercial products are mentioned solely for the purpose of providing specific information; their mention does not imply recommendation or endorsement over others not mentioned.

\section{Conflict of interest}

Author declares there is no conflict of interest in publishing the article.

\section{References}

1. If your clothes aren't already made out of plastic, they will be. 2015 .

2. Annual Cotton Report of Turkish Republic Ministry of Custom and Trade-2015, Turkish; 2016.

3. Cotton: Review of World Situation. International Cotton Advisory Committee. 2013;63(3):1-24.

4. An Interpretative Summary of the Study on: Pesticide use in cotton in Australia, Brazil, India, Turkey and the USA.

5. http://farmhub.textileexchange.org/learning-zone/growing-regions

6. 2013 and Preliminary 2014 US. Organic Cotton Production \& Marketing Trends. 2015. p. 1-12.

7. Ferrigno S, Lizarraga A, Nagarajan P, et al. Organic Cotton Farm And Fiber Report 2009 Executive Summary. 2009. p. 1-6.

8. Unsal A, Organic Cotton Production and Marketing in Turkey.

9. International Cotton Advisory Committee, Limitations On Organic Cotton Production, The ICAC Recorder. 2003.

10. http://www.organiccotton.org/oc/organic-cotton/markets/markets.php

11. http://www.thetextilethinktank.org/organic-cotton-report/

12. http://www.textileexchange.org

13. https://www.oeko-tex.com/en/business/certifications_and_services/ ots_100/ots_100_start.xhtml

14. http://www.nordic-ecolabel.org/

15. https://www.icac.org/cotton_info/tis/organic_cotton/ documents/2003/e_march.pdf

16. Eyhorn F, Ratter SG, Ramakrishnan M. Organic Cotton Crop Guide, A Manual For Practitioners In The Tropics. 2005. 